\title{
Os diálogos da antropologia com a saúde: contribuições para as políticas públicas ${ }^{1}$
}

\author{
Esther Jean Langdon \\ Universidade Federal de Santa Catarina \\ Instituto Brasil Plural
}

Boa noite. É uma honra de ser convidada para proferir essa aula inaugural que celebra o início do Programa de Pós-Graduação em Antropologia Social na Universidade Federal de Mato Grosso (UFMT). Quando cheguei a Florianópolis, em 1983, a antropologia na Universidade Federal de Santa Catarina (UFSC) estava numa situação similar. Entre os docentes do Mestrado em Ciências Sociais, fundado em 1979, apenas três dos 10 professores tinham doutorado em Antropologia e, por ser fora do eixo de São Paulo, Rio de Janeiro e Brasília, era considerado um programa de pós-graduação da periferia. Tivemos problemas durante vários anos em atrair professores para as vagas existentes uma vez que separamos da Sociologia Política para estabelecer o Mestrado em Antropologia Social. Lembro de concursos sem candidatos e outros em que o candidato selecionado optou por não assumir o cargo. Estamos hoje com um Programa de Doutorado em Antropologia, criado em 1999, atualmente com 25 professores, vários deles com destaque nacional. O Programa também é a sede do INCT Brasil Plural (IBP), um dos três Institutos Nacionais de Ciência e Tecnologia com concentração em Antropologia, em um total de 129 INCT criados no Brasil. Como coordenadora do IBP, tenho orgulho deste fato, dado que a maioria dos Institutos é dedicada à tecnologia, à colaboração com empresas e às ciências naturais. Pensando em nosso processo na UFSC, posso afirmar que um futuro de crescimento e consolidação espera este novo programa na UFMT também. Agradeço a oportunidade de participar neste momento.

Apesar de não conseguir largar meu sotaque forte - por ter nascido no país errado - como dizem meus amigos, a vinda ao Brasil resultou em uma mudança altamente positiva para mim. Aprendi uma outra Antropologia, que é bastante diferente da que me foi ensinada nos Estados Unidos. Na preparação das primeiras disciplinas aqui, me dediquei a ler toda a produção brasileira que pude, aprendendo novas maneiras de pensar tópicos familiares. Foi uma experiência

${ }^{1}$ Palestra proferida como aula inaugura do Programa de Pós-Graduação em Antropologia Social da Universidade Federal de Mato Grosso, no dia 22 de abril de 2014. 
que revelou o pluralismo de Antropologias e como cada Antropologia, independente de sua participação na cena acadêmica internacional, reflete as preocupações nacionais e práticas locais.

Pretendo hoje falar sobre o desenvolvimento da Antropologia de Saúde como um campo acadêmico no Brasil através de dois temas muito caros para nossa prática antropológica: o diálogo e o pluralismo de saberes. Seguindo a pensamento de Roberto Cardoso de Oliveira (1998), a Antropologia brasileira se fundamenta no diálogo e no ouvir, respeitando outros saberes e criando uma relação simétrica.

No primeiro momento podemos pensar no pluralismo de saberes que existe entre as Antropologias. Não só porque os subcampos têm suas especificidades, mas também porque as Antropologias, nacionais ou regionais, sejam estas a brasileira, a norte-americana ou a japonesa, são emolduradas por contextos históricos e particulares. Não há uma Antropologia universal, mas várias Antropologias. Cada Antropologia emerge de uma história particular, local e regional. Não é novo o reconhecimento de que os conceitos e problemáticas desenvolvidos por qualquer Antropologia emergem de um contexto sócio-histórico específico. Max Weber, o importante teórico da Sociologia e da Antropologia, já apontou para a subjetividade das Ciências Sociais no início do século XX, reconhecendo que elas propõem diálogos e questões contextualizados a partir de histórias e valores específicos. Não são perguntas universais e nem objetivas. Não existe uma Antropologia única, nem um conhecimento universal.

Para somar ao tema dos pluralismos, a Antropologia da Saúde vem argumentando que existem muitos "saberes médicos". O saber oficial, no Brasil, é o biomédico: o sistema de saberes e práticas fundamentado em uma visão mecânica e biológica do corpo. Porém, há outras tradições médicas presentes na sociedade contemporânea. No Brasil, a acupuntura, a homeopatia e a antroposofia representam tradições validadas e incorporadas ao Sistema Único de Saúde (SUS), com presença importante nos serviços de saúde. E há também as "medicinas complementares", tais como o termalismo, a fitoterapia, os Florais de Bach, a aromaterapia, vários tipos de massagens, entre outras. Algumas delas já têm legitimação no SUS via legislação recente, com a Política Nacional de Práticas Integrativas e Complementares, de 2006. Certas práticas podem ser consideradas expressão da vertente da New Age, na qual a espiritualidade e saúde têm uma conexão forte. Por outro lado, há as tradições populares ou étnicas, tais como o catolicismo popular, os rezadores, benzedores, parteiras e ervateiros, entre uma diversidade de curadores. Essa multiplicidade médica brasileira conta também com os especialistas em cura pertencentes a grupos étnicos, tais como pajés ou pais de santo. Todas essas práticas e especialistas servem, em um momento ou outro, como recursos importantes para a manutenção da saúde.

Faz quatro décadas que a Antropologia vem construindo seus próprios paradigmas sobre a saúde, examinando as práticas de atenção à saúde bem como a produção de corpos pela mediação social, cultural e política. A intenção dos antropólogos que enfocam o tema saúde não é desenvolver práticas de atenção à saúde, mas sim descobrir o quê fazem os grupos específicos da população para atender sua saúde, visando à produção de conhecimento para subsidiar as políticas e os serviços de saúde. Por incluir várias dimensões que não fazem parte dos saberes médicos oficiais, a Antropologia propõe uma visão alternativa à da biomedicina sobre os processos de saúde/doença. Não há uma rejeição da ciência biomédica como um saber. Na década de 1970, Arthur Kleinman, médico e antropólogo, definiu a biomedicina como um sistema cultural, igual a outros 
sistemas culturais como o parentesco, a política, a economia ou a religião. Segundo ele, a biomedicina também deve ser pensada como um sistema cultural e não como uma ciência universal. A Antropologia procura apontar seus limites em entender a complexidade dos processos de saúde/doença, bem como indicar outras dimensões que interferem no adoecer e curar.

A Antropologia da Saúde reconhece que os saberes locais têm igual importância nos processos de saúde e doença, apesar de serem pouco reconhecidos pela ciência médica. Esses saberes envolvem práticas e interpretações de coletividades para manter sua reprodução biossocial, orientam as interpretações e ações que as pessoas colocam em prática quando enfrentam os infortúnios e aflições da vida, porém abarcam dimensões que não fazem parte do domínio da saúde no paradigma biomédico. Por serem saberes e tradições orais, são altamente dinâmicos, com uma capacidade extraordinária de expropriar outros saberes através da experiência. São recursos que precisam ser respeitados como parte do pluralismo de saberes e por seu papel central na procura de tratamentos de saúde pelos atores sociais.

A Antropologia da Saúde, com seu enfoque social, cultural e político, não existia como linha de pesquisa reconhecida no Brasil quando cheguei como professora visitante no começo da década de 1970. Ao chegar no país com formação norte-americana, com ênfase na Antropologia Médica, e tendo 10 anos de experiência com alunos de enfermagem, fiz a proposta de ministrar Antropologia Médica como minha primeira disciplina na UFSC. Lembro a perplexidade de meus colegas, que alegavam que a Medicina não é do domínio da Antropologia. Repetindo Kleinman, argumentei que se tratava de estudar a construção de práticas e saberes em saúde como processos socioculturais, considerando as dimensões normalmente excluídas pela biomedicina. Tive sorte de poder acompanhar e contribuir para a consolidação da Antropologia da Saúde no Brasil desde essa época. Como linha de pesquisa, a Antropologia da Saúde surgiu da Antropologia mais clássica praticada no país em relação com a Saúde Coletiva, a qual unia preocupações políticas e sociais com uma visão crítica de saúde. Neste sentido, a Antropologia da Saúde brasileira se distingue da Antropologia Médica com origem no hemisfério norte.

Minha primeira experiência de conhecer antropólogos e sanitaristas preocupados com os contextos políticos e econômicos brasileiros aconteceu na $1^{\mathrm{a}}$ Conferência Nacional de Proteção à Saúde dos Povos Indígenas, em 1986. Esta experiência estabeleceu os rumos das pesquisas que venho desenvolvendo no Brasil, orientadas conceitualmente por teorias antropológicas, mas que procuram ter relevância para o desenvolvimento das políticas públicas de saúde direcionadas aos povos indígenas. Aquela Conferência também deu origem a uma rede de pesquisadores importante, composta por antropólogos, médicos, enfermeiros, farmacólogos, nutricionistas e sanitaristas, que reuniu profissionais preocupados com o desenvolvimento da política de saúde indígena frente à implantação do SUS. A pesquisa em saúde indígena tem me permitido, durante todos esses anos, a possibilidade de praticar uma Antropologia que não se limita às paredes do mundo acadêmico. Certamente esta foi uma das razões porque optei ficar no Brasil e não voltar para minha universidade de origem. Encontrei no Brasil uma Antropologia rica e inovadora em discussões teóricas, com um olhar crítico e práticas de pesquisa relevantes para o país.

Assim, radicar-me no Brasil resultou muito mais transformador do que minha experiência na Colômbia, onde fui pesquisadora no Central Internacional de Medicina/ Universidad del Valle-Tulane University, entre 1970 e 1974. Lá 
gozei de um visto de diplomata e recebia minha bolsa em dólares. Passei a maior parte daquele período vivendo entre os índios Siona da região amazônica, distante das preocupações cotidianas e nacionais dos colombianos. No Brasil não foi assim. Fui inserida na classe média brasileira como professora e funcionária pública, no final da ditadura militar, em meio a greves universitárias prolongadas e manifestações políticas pelas "Diretas Já". Não só aprendi outra Antropologia, mas também me adaptei a um mundo de incertezas, com uma economia instável de hiperinflação e uma democracia em construção. Penso que é importante reconhecer que a Antropologia da Saúde nasce nessa época, na década de 1980, em torno do projeto democrático e da reforma sanitária. Os pesquisadores estavam engajados diante de possibilidades e implicações da nova ordem de direitos humanos que se estabeleceram na Constituição Federal de 1988.

Tenho trabalhando nos últimos 30 anos com a questão da saúde indígena, principalmente com temas relacionados à noção de atenção diferenciada contida na Política Nacional de Atenção à Saúde dos Povos Indígenas. Mantenho uma discussão crítica sobre a política de interculturalidade, bem como sobre sua operacionalidade e adequação à diversidade indígena brasileira. Além das pesquisas sobre práticas de autoatenção entre vários grupos, indígenas ou não, também venho pesquisando com minha equipe as práticas dos agentes indígenas de saúde e dos conselhos de saúde; a participação e autonomia das organizações indígenas na gestão e planejamento de seus serviços; o tratamento diferenciado de patologias crônicas entre povos indígenas, como por exemplo diabetes; como também os fatores estruturais associados a problemas de abuso de bebidas alcoólicas e doenças mentais. Todos esses são temas relacionados à questão dos serviços de saúde e diversidade cultural.

Além de pesquisa, tenho me esforçado para manter um diálogo aberto com os profissionais de saúde que trabalham com povos indígenas, na atenção primária, através de cursos e outras atividades de formação. Participei durante vários anos da Comissão Intersetorial de Saúde Indígena (CISI), ligada ao Conselho Nacional de Saúde, e do Conselho Distrital de Saúde Indígena do Distrito Sanitário Especial Indígena Interior Sul (CONDISI Interior Sul), bem como de oficinas com os índios organizadas pela Fundação Nacional do Índio, Fundação Nacional de Saúde ou por Secretarias Municipais de Saúde. O diálogo com os profissionais de saúde é fundamental. Apesar de sua visão sobre as práticas de saúde entre povos indígenas ser inspirada, em grande parte, pela visão biológica e médica, eles compartilham as preocupações dos antropólogos e outros pesquisadores sobre saúde indígena. Precisamos manter diálogo com esses profissionais da mesma maneira que nos esforçamos para dialogar com indígenas ou outros grupos que pesquisamos. Às vezes, como antropólogos, ficamos encerrados em uma opinião fechada presumindo que nossa disciplina tem todas as respostas. As realidades de saúde e as políticas de saúde, seja dos indígenas ou da população em geral, apresentam situações altamente complexas. No Brasil a saúde é uma realidade multidimensional que não pode ser resolvida por um único campo de saberes ou de ações, tal como Medicina, Saúde Coletiva ou Antropologia.

\section{Dialogo interdisciplinar}

É aqui que gostaria de pensar em outra Antropologia no plural, uma Antropologia que valoriza e procura dialogar com saberes de outras disciplinas. No 
caso da formação da Antropologia da Saúde brasileira, o diálogo com a Saúde Coletiva tem sido central na constituição desta linha de pesquisa.

A reforma sanitária na América Latina e o desenvolvimento do campo da Saúde Coletiva, na década de 1980, são caracterizados pelo reconhecimento da importância das dimensões sociais, culturais e políticas nos processos de saúde e, também, pela tentativa de buscar nas Ciências Sociais uma visão mais além da epidemiologia estatística. A Saúde Coletiva, conhecida como Medicina Social em outros países, é mais bem definida como um movimento sociopolítico em vez de apenas um movimento médico. É formada por sanitaristas e outros atores preocupados com o direito universal à saúde em contextos de iniquidade e que trouxeram uma visão crítica ao olhar biologicista do paradigma biomédico.

A Saúde Coletiva é um fenômeno latino-americano e a natureza deste campo, tanto quanto suas problemáticas, são pouco entendidas fora dessa região. Penso que essa falta de compreensão é devida ao assunto que levantei antes, que as perguntas feitas pelos latino-americanos sobre suas políticas de saúde emergem de contextos políticos, econômicos e sociais muito diferentes do hemisfério norte. Minha experiência de diálogo com meus colegas dos Estados Unidos indica que não há entendimento do que é esse movimento, talvez por ser originado pelo argentino Juan César García (Nunes, 1989), um médico, sociólogo, intelectual e pesquisador da vertente marxista. Intelectual preocupado com a relação entre saúde, medicina e sociedade, ele teve um papel central neste campo do conhecimento que se iniciava na América Latina nos anos 1960. Trabalhou na Organização Pan Americana da Saúde (OPAS) durante dezoito anos e tinha uma influência importante na pesquisa e em programas de atenção à saúde na América Latina. Entre os vários outros latino-americanos importantes no campo de saúde, política e ciências sociais, contamos com o brasileiro Sérgio Arouca, que participou no movimento da Saúde Coletiva no país.

Desde a década de 1960, iniciou-se uma rede em quase todos os países da América Latina, formada por pesquisadores e ativistas do movimento sanitário. Em 1972, a OPAS realizou uma reunião em Cuenca, Equador, com o fim de examinar o quadro sanitário latino-americano usando o marco teórico do marxismo histórico-estrutural para entender o papel da instituição médica. Iniciouse, assim, uma nova direção nas pesquisas das Ciências Sociais em saúde, particularmente da Sociologia, que diverge do enfoque no médico e nas relações médico-paciente. A reunião chamou atenção para a necessidade de reformas nas políticas de saúde e de um modelo alternativo em medicina que examine as contradições internas dos sistemas de saúde, bem como as relações da saúde com os modos de produção e as formas socioeconômicas. Ainda, que esse modelo alternativo defina epistemologicamente as relações entre ciências biológicas e sociais e que explicite o papel da intervenção do Estado. Segundo Nunes (1999), as deliberações desta reunião passaram a ser a marca de identidade e de legitimação da Saúde Coletiva, incluindo a participação das Ciências Sociais.

A rede de sanitaristas e cientistas sociais teve continuidade desde então, realizou várias conferências e fóruns, bem como promoveu a formação de organizações, tais como a Associação Brasileira de Saúde Coletiva (ABRASCO), em 1979; a Associação Latino-Americana de Medicina, em 1984; o Fórum LatinoAmericano de Ciências Sociais e Medicina; Associação Latino-Americana de Medicina Social (ALAMES); entre vários outros. Os encontros realizados por essas organizações científicas foram apoiados, desde a década de 1990, frequentemente, pelo Fórum Internacional de Ciências Sociais e Saúde (IFSH), pela Corporação Carnegie de Nova York, pela Fundação Ford, pela Fundação 
LANGDON, Jean.

Os Diálogos da Antropologia com a Saúde

Rockefeller e pelo Centro de Investigações pelo Desenvolvimento Internacional (IDRC/CRDI) do Canadá (veja Tabela I). 
Tabela I: Encontros de medicina com participação de cientistas sociais

\begin{tabular}{|c|c|c|}
\hline DATA & EVENTO & PAÍS \\
\hline 1991 & $1^{\circ}$ Congresso Latinoamericano de Ciências Sociais e Medicina & Chile \\
\hline 1993 & Fórum Latino-Americano de Ciências Sociais e Medicina & Argentina \\
\hline 1994 & Fórum Internacional de Ciências Sociais e Saúde & Venezuela $^{2}$ \\
\hline 1995 & $\begin{array}{l}\text { III Congresso Latinoamericano de Ciências Sociais e Medici- } \\
\text { na /I Congresso Brasileiro de Ciências Sociais em Saú- } \\
\text { de/ABRASCO }\end{array}$ & $\begin{array}{l}\text { Curitiba, Bra- } \\
\text { sil }\end{array}$ \\
\hline 1997 & $\begin{array}{l}\text { IV Congresso Latinoamericano de Ciências Sociais e Medici- } \\
\text { na }\end{array}$ & Mexico $^{3}$ \\
\hline 1999 & V Congresso Latinoamericano de Ciências Sociais e Medicina & Venezuela $^{4}$ \\
\hline 1999 & $\begin{array}{l}\text { II Congresso Brasileiro de Ciências Sociais e Humanas em } \\
\text { Saúde/ ABRASCO }\end{array}$ & $\begin{array}{l}\text { São Paulo, } \\
\text { Brasil }\end{array}$ \\
\hline 2001 & $\begin{array}{l}\text { VI Congresso Latinoamericano de Ciências Sociais e Medici- } \\
\text { na }\end{array}$ & Peru $^{5}$ \\
\hline 2003 & $\begin{array}{l}\text { VII Congresso Latinoamericano de Ciências Sociais e Medi- } \\
\text { cina }\end{array}$ & Brasil $^{6}$ \\
\hline 2005 & $\begin{array}{l}\text { III Congresso Brasileiro de Ciências Sociais e Humanas em } \\
\text { Saúde/ ABRASCO }\end{array}$ & $\begin{array}{l}\text { Florianópolis, } \\
\text { Brasil }\end{array}$ \\
\hline 2006 & $\begin{array}{l}\text { Seminario "El Planteamento de una epidemiologia } \\
\text { sociocultural" }\end{array}$ & $\begin{array}{l}\text { Cuernavaca, } \\
\text { Mexico }^{7}\end{array}$ \\
\hline 2007 & $\begin{array}{l}\text { IV Congresso Brasileiro de Ciências Sociais e Humanas em } \\
\text { Saúde - ABRASCO/X Congresso da Associação Latino- } \\
\text { Americana de Medicina Social/XIV Congresso da Associação } \\
\text { Internacional de Política de Saúde }\end{array}$ & $\begin{array}{l}\text { Salvador, Bra- } \\
\text { sil }\end{array}$ \\
\hline 2011 & $\begin{array}{l}\text { V Congresso Brasileiro de Ciências Sociais e Humanas em } \\
\text { Saúde/ ABRASCO }\end{array}$ & $\begin{array}{l}\text { São Paulo, } \\
\text { Brasil }\end{array}$ \\
\hline 2012 & $\begin{array}{l}\text { XII Congresso Latino-Americano de Medicina Social/XIII } \\
\text { Congresso Internacional de Política em Saúde/IV Congresso } \\
\text { da Rede dos Actores Locais em Saúde }\end{array}$ & Uruguay \\
\hline 2013 & $\begin{array}{l}\text { VI Congresso Brasileiro em Ciências Sociais e Huma- } \\
\text { nas/ABRASCO }\end{array}$ & $\begin{array}{l}\text { Rio de Janeiro, } \\
\text { Brasil }\end{array}$ \\
\hline 2014 & $\begin{array}{l}\text { XIII Congresso Latino-Americano de Medicina Social e Saú- } \\
\text { de Coletiva }\end{array}$ & El Salvador \\
\hline
\end{tabular}

Como todos aqui devem saber, a ABRASCO é a maior organização em Saúde Coletiva da América Latina, hoje em dia com mega reuniões no campo da epidemiologia. Desde 1995, a ABRASCO também realiza congressos com o tema específico de ciências sociais e saúde na Universidade Estadual do Rio de Janeiro (UERJ) e conta com mais de 1600 pessoas, entre as quais muitos antropólogos brasileiros e de outros países latino-americanos.

\section{O desenvolvimento da Antropologia da Saúde no Brasil}

\footnotetext{
2 Anais - Briceño-León, R. 1999.

3 Anais - Bronfman, M. \& R. Castro. 1999.

4 Anais - Briceño-León, R., M.C. de S. Minayo, C.E.A. Coimbra Jr., 2000.

5 Anais - Cáceres, Carlos, M. Cueto, M. Ramos e S. Vallenas 2003.

${ }^{6}$ Anais - Minayo, M.C. de S. E C.E.A. Coimbra Jr. 2005.

7 Anais - Haro, J. A. Epidemiología sociocultural. Un diálogo en torno a su sentido, métodos y alcances.
} 
Os primeiros antropólogos brasileiros a pesquisar práticas de saúde que voltaram do exterior com seus doutorados em Antropologia se instalaram em programas em saúde. Lembro que antes de estar consciente da relação entre Antropologia e Saúde Coletiva, eu fiquei perplexa com o fato de Marcos Queiroz, com doutorado na Inglaterra, e Maria Andrea Loyola, com doutorado na França, voltarem ao Brasil no início da década de 1980 para serem incorporados em faculdades médicas e não em departamentos de antropologia. A afiliação de Queiroz e Loyola na Medicina Social da Universidade Estadual de Campinas (UNICAMP) e no Instituto de Medicina Social da UERJ, respectivamente, reflete a tendência interdisciplinar e a preocupação com a política presente na origem da linha de estudos em saúde da Antropologia.

Porém, a Antropologia da Saúde não forma um subcampo especializado, considerando que os antropólogos que atuam nessa linha continuam engajados, em primeira instância, com questões teórico-analíticas da Antropologia que circulam no país. Esses antropólogos não se caracterizam por discussões especializadas que se encerram em uma visão do corpo como dado primeiramente biológico, da maneira que Luiz Fernando Duarte assinala ser o caso da Antropologia Médica norte-americana.

Isso é evidente no projeto que inaugurou as pesquisas na Antropologia da Saúde no Brasil, na década de 1970. Ele foi proposto por professores dos recém formados Programas de Pós-Graduação em Antropologia Social da Universidade de Brasília e do Museu Nacional, e financiado pela Financiadora de Estudos e Projetos (FINEP). Intitulado Hábitos e Ideologias Alimentares em Grupos Sociais de Baixa Renda, o projeto visava a identificar o impacto do desenvolvimento e o momento político e econômico do país nas práticas cotidianas. Foram realizadas pesquisas sobre representações culturais e hábitos alimentares, sendo os resultados analisados a partir dos paradigmas do estruturalismo francês e da antropologia simbólica. Os estudos foram feitos entre camponeses, comunidades de pescadores e trabalhadores da agricultura e da indústria, com o objetivo de entender como as forças políticas e econômicas influenciavam as estratégias de subsistência. Esse projeto estabeleceu a agenda de pesquisa em saúde, delineada a partir de conceitos e paradigmas contemporâneos, com poucas referências aos debates que circulavam na Antropologia Médica dos Estados Unidos e tampouco se identificava com a linha de pesquisas da Antropologia da Saúde.

Na década de 1980, o diálogo com a Saúde Coletiva e sua crítica a respeito do enfoque biologicista, universalista e individualista da biomedicina já estava presente. Em uma revisão que procurou avaliar a direção da "Antropologia das Medicinas” em construção no Brasil, Queiroz e Canesqui (1986a; 1986b), ambos associados ao Centro de Ciências Médicas da UNICAMP, salientaram a necessidade de se desenvolver paradigmas capazes de analisar a subordinação ao modelo capitalista de processos sociais locais relacionados à saúde, refletindo a receptividade das vertentes marxistas presente na Saúde Coletiva. Nas pesquisas etnográficas, os antropólogos preocupados com as relações entre a biomedicina e as práticas locais de saúde procuraram desenvolver paradigmas alternativos à abordagem biológica e quantitativa, dominante no campo da saúde pública e em pesquisas epidemiológicas.

Com a chegada do início da década de 1990, a visibilidade de antropólogos e outros profissionais com pesquisas em Ciências Sociais e saúde começa a aumentar e se forma uma rede bastante variada de antropólogos e profissionais de saúde. Em 1993, o $1^{\circ}$ Congresso de Antropologia Médica foi realizado na Bahia, com participantes da Saúde Coletiva e da Antropologia. Apesar de nunca ter si- 
do realizado um segundo Congresso e de o rótulo de "médica" ter sido suplantado por "da saúde", aquela década foi importante para o crescimento e diversidade das pesquisas em questões sociais e culturais de saúde no Brasil. Certamente, esse crescimento foi influenciado não só pela implantação do SUS, com seus princípios de humanização, democratização e participação, mas também pela agenda internacional em saúde definida nos documentos da Organização Mundial de Saúde (OMS), da OPAS e outros, como a Convenção 169 da Organização Internacional do Trabalho.

Outro fator a dar visibilidade para a Antropologia da Saúde foi o crescimento alarmante de casos de AIDS no Brasil e na África, um problema cujas causas sociais, culturais e econômicas precisavam ser entendidas para alcançarse efetivo controle e prevenção da doença. A agenda internacional foi importante ainda na definição de outras doenças prioritárias, de grupos de risco e dos direitos de grupos minoritários. Agências internacionais contribuíram com recursos aos programas nacionais em saúde direcionados para certas temas e grupos alvos, como AIDS/DST, sexualidade, abuso de bebidas alcoólicas, saúde da mulher e da criança, doenças endêmicas e doenças crônicas como diabetes, obesidade etc. Esses recursos também estimularam as pesquisas nas áreas de ciências sociais por meio de editais publicados pelo Ministério de Saúde, geralmente em conjunto com CNPq. Começamos a ver, na década de 1990, a publicação de vários editais sobre problemas específicos em saúde que incluíam dimensões para pesquisa social. O desenvolvimento e o rumo das pesquisas em Antropologia da Saúde também foram influenciados por esses novos recursos.

Como exemplo da influência da agenda global em saúde, posso citar o Programa Nacional de DST/AIDS, que teve um impacto importante no desenvolvimento do campo por incluir pesquisadores e organizações não-governamentais preocupadas com os fatores sociais, tais como práticas sexuais, relações de gênero etc., na transmissão da doença. Na segunda parte da década de 1990, época em que o Brasil estava entre os países com o maior número de casos de AIDS, o Programa recebeu recursos financeiros do Banco Mundial que superaram o orçamento do Ministério de Saúde para todos os seus demais programas. Este Programa foi importante, não só pela quantidade de recursos alocados do Banco Mundial (com contrapartida do governo brasileiro), mas também pelo foco nos direitos ao acesso universal à saúde, nos aspectos discriminatórios da doença e por incluir organizações não-governamentais e outros setores da sociedade civil no combate e na prevenção da doença, tanto quanto na formulação da política (Monteiro e Villela, 2009).

Em 1996, foi criado o componente indígena do Programa Nacional de DST/AIDS sob a coordenação de um médico que realizava seu Mestrado em Antropologia na UFSC. Uma sequência de reuniões regionais foi financiada pelo Programa, juntando pesquisadores universitários, organizações nãogovernamentais e lideranças indígenas, com o fim de elaborar propostas para a realização de oficinas de prevenção em DST/AIDS através da formação de multiplicadores nas comunidades indígenas. O Núcleo de Estudos sobre Saúde e Saberes Indígenas (NESSI-UFSC) submeteu o projeto Prevenção das Doenças Sexualmente Transmissíveis e AIDS junto à População Indígena de Santa Catarina e recebeu financiamento do Ministério de Saúde. Oficinas de treinamento de multiplicadores foram conduzidas em parceria com uma organização nãogovernamental local e os profissionais do Departamento de Saúde Indígena da Fundação Nacional de Saúde. O grupo depois participou de outras conferências e atividades, com alcance em nível regional, nacional e internacional, as quais 
contavam com pesquisadores de outras universidades, ativistas e profissionais de saúde. A meu ver, este Programa teve papel central no estímulo de conferências e pesquisas sobre saúde indígena entre 1995 e 1999.

\section{Redes e o desenvolvimento de conceitos próprios}

Roberto Cardoso de Oliveira (1999-2000), em um artigo publicado em inglês sobre a Antropologia brasileira, usa os termos "periférica" e "metropolitana" para falar das Antropologias mundiais e suas tensões. Assim como outros autores que trabalham com o desenvolvimento de novos paradigmas (Restrepo e Escobar, 2005), ele reconheceu os esforços das Antropologias periféricas para alcançar autonomia e um desenvolvimento efetivo em escala global. Entre os indicadores sugeridos por Cardoso de Oliveira para identificar a consolidação de uma antropologia outra está o desenvolvimento de um perfil metateórico independente dos paradigmas eurocêntricos. Em outras publicações (Langdon e Follér, 2012; Langdon, Follér e Maluf, 2012), temos avaliado a capacidade da Antropologia brasileira em buscar construir seu próprio paradigma sobre corpo, tanto na Etnologia Indígena quanto na Antropologia da Saúde.

Aqui gostaria de apresentar alguns paradigmas que a rede de pesquisadores latino-americanos vem propondo e discutindo para orientar investigações as quais procuram lidar com preocupações locais e nacionais em saúde. São paradigmas que expressam nossas particularidades e nos distinguem das Antropologias metropolitanas. O desenvolvimento de conceitos nas Ciências Sociais é um processo altamente dinâmico, pois reflete contextos histórico-sociais e preocupações específicos (Weber 1986).

O conceito não tem a função de identificar categorias reais no mundo social, mas de orientar o olhar para facilitar uma compreensão possível de certa realidade e com certas preocupações - ambos aspectos que mudam no devir da vida social. Estou argumentando que nesta rede da Antropologia da Saúde estamos empenhados no desenvolvimento de conceitos que reflitam a perspectiva, as situações e preocupações latino-americanas. Tal empreendimento gera conceitos particulares para direcionar o olhar. Um desafio que marca as investigações na América Latina é entender a pluralidade nas práticas de saúde, bem como as articulações dinâmicas e criativas que as coletividades colocam em ação buscando resolver seus infortúnios. Não se trata de categorizar essas práticas como crenças, como subculturas ou como sistemas. Observando as práticas dinâmicas que as coletividades articulam para sua reprodução sociobiológica, a definição de "práticas de saúde" necessariamente se alarga, amplia e estende bem além da visão limitada da biomedicina. Esse é o desafio para a Antropologia da América Latina, cuja realidade e preocupações diferem da dos Estados Unidos, onde a hegemonia da biomedicina é muito mais forte e outras práticas, ligadas a medicinas complementares, alternativas, religiosas ou populares, são deslegitimadas.

Uma característica que diferencia a rede da América Latina da Antropologia Médica dos Estados Unidos é a construção da perspectiva crítica. A perspectiva crítica nos Estados Unidos iniciou na década de 1980 e se instalou na década seguinte de forma hegemônica e com uma visão que parte da posição global do país. Porém, os intelectuais da América Latina estavam com uma perspectiva crítica décadas antes, certamente devido à sua posição na ordem mundial, reconhecida por Darcy Ribeiro quando reformulou as teorias neoevolucionistas (1968) e introduziu a noção de dependência. Mesmo que muitos aqui presentes 
possam desconsiderar sua contribuição, alguns antropólogos e cientistas sociais consideram a reformulação de Ribeiro como uma teoria portadora de um projeto alternativo ao paradigma eurocêntrico no âmbito internacional (Meggers, 1968; Arruti, 1997; Ribeiro, 2011). Ainda na década de 1960, Gilberto Freyre, em diálogo com uma vertente anglo-saxônica, propõe uma abordagem biocultural articulada entre saúde, doença e cultura e suas especificidades no ambiente e na cultura dos trópicos como instrumento para uma política sanitária adaptada à região (Freyre, 1967; Bertolli Filho, 2003).

Uma contestação à perspectiva norte-americana nas investigações em saúde foi apresentada pelo mexicano Guilherme Bonfil Batalla e publicada, em 1966, numa revista norte-americana de ampla divulgação. Neste artigo ele já levanta a perspectiva de que a estrutura socioeconômica é a maior determinante da situação deplorável de saúde das populações subalternas na América Latina - e não as crenças culturais. Esta crítica foi feita à Antropologia aplicada dos Estados Unidos, que deu origem à Antropologia Médica, e cuja perspectiva culturalista da época procurava identificar práticas e crenças culturais que se constituíam como obstáculos para a aceitação de projetos de desenvolvimento e saúde. A visão crítica esteve presente na perspectiva latino-americana décadas antes de a Antropologia Médica incorporar os fatores de poder e iniquidade em seus modelos analíticos. E dou graças a Deus que vim para o Brasil aprender em primeira mão a perspectiva do Sul.

Esta perspectiva do Sul reconhece que as condições de saúde e as práticas das pessoas são resultantes dos processos hegemônicos e das forças de poder, não de práticas culturais ou da falta de conhecimento. Desde o começo, essa visão crítica vem sendo inspirada pelos pensadores marxistas, como os da Escola de Frankfurt, Foucault, Gramsci e outros, mais atuais, como Seppilli (Itália), Bibeau (Canadá), Fassin (França) e Menéndez (México). Os pesquisadores desta linha distanciam-se das indagações feitas pelos antropólogos que definiram seu papel como o de tradutores da cultura em projetos de saúde e são taxativos em insistir que seus trabalhos não estão a serviço do médico ou da medicina oficial, como na Antropologia aplicada. Eles vêm desenvolvendo conceitos teóricometodológicos adequados para entender a situação da América Latina.

Em nossas pesquisas, podem-se identificar três eixos relacionados ao processo de saúde/doença, os quais pretendem contribuir para o diálogo entre saúde e política. O primeiro eixo privilegia as relações entre a biomedicina e as práticas de saúde locais, especialmente entre as políticas de saúde e/ou inclusão empreendidas pelo Estado e as formas através das quais as populações específicas dão respostas a essas mesmas políticas. O segundo enfatiza as práticas terapêuticas e os especialistas em saúde locais, assim como a emergência de novas formas de atenção à saúde. Já o terceiro eixo compreende a tentativa de desenvolver conceitos capazes de descrever as dinâmicas envolvidas nas práticas de saúde empreendidas pelos sujeitos em contextos etnográficos específicos, ressaltando as relações dessas práticas com processos sociocosmológicos e vivenciais.

Esses eixos teórico-metodológicos partem de paradigmas que analisam o processo de saúde/doença (Langdon, 1994) como um fenômeno socialmente construído e contextual (Young, 1976), bem como da premissa que os diferentes sistemas médicos (Kleinman, 1973) possuem especificidades e estão em constante reconfiguração e interlocução (Follér, 2004; Greene, 1998). Nossas pesquisas também ressaltam o caráter dinâmico e processual das práticas ligadas ao cuidado da saúde, bem como as ações de articulação entre diferentes conhe- 
cimentos e saberes, com o intuito de descrever e analisar as particularidades, interações, negociações e conflitos existentes nos processos sociais.

O NESSI-UFSC está em rede com instituições como Universidade de Brasília (UnB), Fundação Oswaldo Cruz (FIOCRUZ), Universidade Federal do Amazonas (UFAM), Universidade Federal do Mato Grosso (UFMT) e Universidade Federal de São Carlos (UFSCar). Nesse momento, a rede privilegia a elaboração de conceitos para buscar compreender as dinâmicas envolvidas nos saberes e práticas de saúde, empreendidos pelos sujeitos em contextos etnográficos específicos. Para nossos objetivos, modelos de atenção à saúde e práticas de autoatenção - conceitos elaborados por Eduardo Menéndez (1982; 2003) - têm sido úteis para entender as chamadas situações interculturais que envolvem atividades de tipo biomédico, o que inclui todos os recursos terapêuticos empregados na busca de prevenção, tratamento, controle, alívio e/ou cura de doenças. Com tais conceitos, o modelo médico hegemônico, com suas características de biologicismo, a-historicidade, a-culturalidade, eficácia pragmática, orientação curativa e medicalização dos padeceres, representa apenas um dos saberes acionados em processos de saúde/doença. Os outros correspondem às práticas terapêuticas populares e alternativas, que englobam conhecimentos populares sobre saúde; as medicinas de povos indígenas; as práticas terapêuticas new age; os grupos centrados na autoajuda; as práticas oriundas de outras tradições médicas acadêmicas; e assim por diante.

As práticas de autoatenção são definidas por Menéndez como:

[A]s representações e práticas que a população utiliza no nível do sujeito e do grupo social para diagnosticar, explicar, atender, controlar, aliviar, aguentar, curar, solucionar ou prevenir os processos que afetam sua saúde em termos reais ou imaginários, sem a intervenção direta, central e intencional de curadores profissionais. (Menéndez, 2009, p.179)

O autor sublinha, portanto, o caráter autônomo dessas práticas. Segundo Menéndez, existem dois níveis nos quais as práticas de autoatenção podem ser pensadas: o primeiro, mais amplo, está ligado a todas as formas de autoatenção necessárias para assegurar a reprodução biossocial dos sujeitos e grupos no nível dos microgrupos, em especial do grupo doméstico. Assim, a autoatenção neste nível inclui, não somente, o cuidado e a prevenção das enfermidades, mas também usos de recursos corporais e ambientais, dietética, normas de higiene pessoal e coletiva, organização social, rituais e assim por diante. O segundo nível, mais restrito, refere-se principalmente às estratégias, científicas e não científicas, de representação da doença e de práticas de cura e cuidados.

Crítico das tendências rápidas de pesquisa em saúde (RAP), Menéndez (2012) defende a pesquisa etnográfica clássica, de longa duração, por centrar-se nos sujeitos e grupos sociais. Desse modo são reveladas as formas pelas quais esses diferentes modelos de atenção se articulam nos itinerários terapêuticos individuais, onde muitas vezes aparecem combinadas práticas terapêuticas e noções sobre saúde/doença definidas como antagônicas ou excludentes em outras instâncias. São os atores sociais, inseridos em redes de trocas de conhecimentos, que constroem influências mútuas entre diferentes modelos de atenção à saúde. Desta maneira, as práticas e concepções a respeito de saúde/doença são construídas e reconstruídas em um processo contínuo, dando lugar à emergência de novos modelos de atenção.

Resumindo, o conceito de autoatenção aponta para o reconhecimento da autonomia e da criatividade da coletividade, principalmente da família, como o 
núcleo que articula os diferentes modelos de atenção ou cuidados de saúde. Diferente do conceito médico de "autocuidado", o conceito de Menéndez desloca a ação do profissional de saúde para os atores como coletividade. Enquanto o primeiro trata da adequação do paciente em incorporar os valores e instruções da biomedicina, o segundo trata de sua autonomia na articulação dos recursos terapêuticos acessíveis, independente de sua origem, e da criação de novas articulações.

Em minha análise sobre os itinerários terapêuticos entre populações indígenas, argumento que o processo de articulação constrói o processo experiencial da doença para o grupo. Ver a doença como experiência implica entendê-la como um processo subjetivo construído através de contextos socioculturais e vivenciado pelos atores (Langdon 2005). O contexto sociocultural é relevante para compreender tanto a definição da doença em si quanto a escolha das práticas de cura empregadas. Dessa maneira, a cosmologia de um grupo é, também, um fator na constituição dos itinerários de diagnóstico e tratamento. Meus argumentos mostram como nos itinerários dos indígenas constroem-se negociações entre elementos provenientes de distintos sistemas terapêuticos e de diferentes cosmologias.

Os enfoques no local, no método etnográfico e na interação revelam a relação com fatores mais amplos de ordem política, econômica e ideológica, sejam eles as hierarquias presentes nos processos de comunicabilidade entre o profissional de saúde e a comunidade que ele atende (Briggs, 2005), sejam as condicionantes inerentes à posição socioeconômica do grupo, que influem em sua saúde e em suas escolhas. As interações e práticas locais refletem os contextos mais globais, revelando as relações de poder nas questões que dizem respeito à vida e à morte ou ameaçam o tecido social. As análises etnográficas ressaltam como as intersecções e articulações entre os fatores de ordem macroestrutural e as formas através das quais saúde/doença são pensadas localmente. Assim, as análises consideram as especificidades dos sistemas médicos particulares como processos regionais, nacionais e globais que transcendem o caráter local.

Outro conceito que tem sido frutífero para ressaltar os aspectos políticos, econômicos e ideológicos envolvidos nas práticas e conhecimentos relacionados à saúde e à doença se expressa no termo intermedicalidade. Esse conceito procura dar conta de contextos caracterizados pela convivência de diversos sistemas médicos e estratégias de poder, originando "sistemas médicos híbridos" (Follér, 2004; Green, 1998). A noção de intermedicalidade permite analisar a realidade social considerando que ela é constituída por negociações entre sujeitos politicamente ativos e destacando que nessas negociações todos os sujeitos envolvidos são dotados de agência social.

Ambos os conceitos, intermedicalidade e práticas de autoatenção, mostram que, apesar da contínua expansão da biomedicina na América Latina, o paradigma biomédico não suplanta outras formas de conhecimento. Pelo contrário, ao mesmo tempo em que a biomedicina se expande, as práticas de saúde populares e alternativas também florescem nos países da América Latina, bem como em outras partes do mundo. Ou seja, as dinâmicas relacionadas aos processos de saúde/doença são caracterizadas por uma negociação entre diferentes práticas e formas de conhecimento, sendo que, muitas vezes, nesse processo se formam novas sínteses e hibridações.

Com base nessas premissas, os paradigmas que estamos desenvolvendo procuram dar conta das diversas formas em que os mais variados sistemas terapêuticos são acionados nos processos de saúde/doença. Procuramos com isso 
ressaltar aspectos como a interação e a relacionalidade inerentes às práticas sociais. As práticas, conceitos e ações dos indivíduos que compõem os grupos sociais articulam-se na ordem sociocosmológica, mas também se encontram ligados à reelaboração de diferentes aspectos do social. O enfoque no aspecto relacional e nas múltiplas vozes que integram o cenário social vincula-se a uma compreensão do caráter emergente e dinâmico das relações sociais imbricadas aos processos de saúde/doença. Ao mesmo tempo, a ênfase na perspectiva do ator social e em sua capacidade de agência (Ortner 2007) aponta para o fato de que é a partir dos sujeitos e/ou grupos sociais que são construídas as articulações entre os diferentes conceitos e práticas relacionados ao processo de saúde/doença. Aponta ainda que, muitas vezes, essas articulações se dão através de ações que recombinam elementos das mais variadas esferas e produzem outros aspectos do social. Esses paradigmas trazem para o campo da saúde coletiva e da elaboração e execução das políticas públicas uma visão da coletividade, de um lado, e, de outro, delimitam o lugar da saúde no plano social, reconhecendo os saberes plurais, a autonomia dos atores e fatores globais que estão presente em situações locais.

\section{Comentários finais}

Os conceitos tratados antes não são os únicos desenvolvidos por pesquisadores latino-americanos capazes de salientar as complexidades da saúde na América Latina. Recentemente, um seminário realizado em Cuernavaca, México, El Planteamento de una epidemiologia sociocultural (Haro, 2011), contou com pesquisadores de vários países no diálogo em torno da adequação do conceito "epidemiologia sociocultural". O antropólogo colombiano Hugo Portela (2008) propõe "epidemiologia intercultural”, conceito que privilegia os saberes e epistemologias indígenas. Por sua vez, Jaime Briehl (2010), médico equatoriano, fala de "epidemiologia crítica", enquanto o brasileiro Naomar de Almeida Filho (2001) junta seus interesses como médico aos seus estudos em antropologia e introduz o conceito "etnoepidemiologia". Poderia citar muitos outros, mas espero que estes sejam suficientes para indicar que a Antropologia da Saúde na América Latina apresenta paradigmas alternativos que têm em conta forças de poderes, situações de dominação e saberes plurais.

Os conceitos refletem uma perspectiva de engajamento crítico, não só no que diz respeito aos fatores estruturais que impactam a saúde das populações latino-americanas, mas também às posições ideológicas implícitas no saber e na prática biomédica. $\mathrm{O}$ modelo biológico de saúde explica em parte o fenômeno, sem contemplar, contudo, os fatores sociais, culturais, políticos e econômicos envolvidos, nem processos e saberes outros introduzidos pelos paradigmas alternativos que estão sendo propostos e comentados aqui. A Antropologia, por sua parte, conceitua corpo como um dado simultaneamente biológico, psicológico e social, que é produzido através da mediação de vários níveis de interação social. Valoriza e analisa os saberes expressados nas práticas de autoatenção e as estratégias que as coletividades desenvolvem para viver bem.

Observando o engajamento da Saúde Coletiva, da Antropologia e de outras Ciências Sociais no sentido de entender a situação e as práticas de saúde locais, para lutar por um sistema de assistência à saúde mais democrático e justo, acho estranho que a Antropologia Médica crítica norte-americana não esteja engajada de maneira semelhante com as políticas de saúde nos Estados Unidos, que são baseadas em um sistema privado de seguros. Ao que parece, estamos preo- 
cupados com questões diferentes e temos níveis de engajamento bem distintos nas pesquisas e no desenvolvimento de nossos saberes acadêmicos. Diferente da Antropologia aplicada, os antropólogos brasileiros nunca aceitaram a aparente instrumentalização da Antropologia pelos serviços de saúde. Porém, as pesquisas que nós fazemos têm relevância para as políticas em saúde. O IBP, que coordeno há seis anos, tem esse objetivo de subsidiar políticas públicas através do fomento a pesquisas antropológicas de longa duração. Os resultados de nossas pesquisas são importantes para a prestação de serviços em saúde, formação de recursos humanos e, também, para estimular a participação, inclusão e universalização. O desenvolvimento de conceitos específicos a este objetivo representa um engajamento epistemológico que leva em conta a existência de saberes plurais.

Nesse sentido, acreditamos que a pesquisa qualitativa de longa duração é em si uma forma de engajamento, tanto prática quanto epistemológica. Voltando a Roberto Cardoso de Oliveira, eu diria que é uma metodologia que procura desenvolver um diálogo simétrico e não hierárquico, em oposição às relações em saúde que privilegiam os saberes e poderes biomédicos.

Em resumo, e agora retornando a pensar sobre a importância da criação deste curso de Pós-Graduação em Antropologia em Mato Grosso, ressalto o valor e as contribuições das Antropologias consideradas periféricas ou emergentes. A Antropologia da Saúde, descrita antes, pode ser considerada da periferia frente à Antropologia Médica eurocêntrica, que pouco nos reconhece, e mesmo frente à Saúde Coletiva e à Antropologia brasileira, que tendem a minimizar a relevância desta nossa linha de atuação para campos acadêmicos mais amplos. Porém, além da relevância política e conceitual como linha de pesquisa, temos um papel na relação da academia com o mundo atual. Assim, por analogia, é possível reconhecer os desafios que seu Programa enfrentará numa região longe do eixo central de São Paulo, Brasília e Rio de Janeiro. Mas é possível também reconhecer suas contribuições potenciais por estar em uma região tão rica em diversidade cultural e por seu engajamento nas problemáticas de pluralidades de saberes e direitos humanos. Mas uma vez, agradeço a oportunidade de estar aqui neste momento.

\section{Perguntas}

Dr. Moises: nós gostaríamos de agradecer muito a fala da professora Jean e nós vamos abrir para dúvidas e questionamentos.

Alguém do auditório: eu acho que é muito importante a Jean, eu estava aqui e ela está falando e eu estava pensando que talvez nós duas sejamos as demandas do auditório. E todas essas coisas que a Jean estava falando, ela são importantíssimas porque hoje há uma grande discussão no Brasil se nós fazemos uma antropologia no Brasil. E eu escuto meus alunos dizerem que não há. E eu afirmo que há. E a compreensão desse diálogo entre a metrópole e aquilo que se chama de periferia não é uma antropologia de má qualidade e aí eu lembro de Roberto Cardoso de Oliveira é importante para que a gente faça uma Antropologia adequada. Não sei se vocês repararam que a Jean dizia assim: 'no nosso Brasil, nós fazemos', então ela se considera uma brasileira, então ela absorveu essa situação de forma que ela critica como ela brincou o país que ela nasceu e nasceu errado né. Então veja, isso é muito importante à gente ouvir uma pessoa que tem essa visão, que veio pra o Brasil e que incorporou isso. Porque às vezes o que a gente faz, a gente não dá o devido valor, a devida importância e eu acho 
que a gente faz uma Antropologia de altíssima qualidade. Agora é verdade que ela não é ouvida fora da América Latina. Agora eu também penso assim: é importante que a gente faça e que a gente não esteja de costas para a América Latina, porque é exatamente por isso que a gente cresceu. Então eu acho que o histórico que a Jean tentou fazer ele não é de nenhuma forma completa porque ela tem uma visão disso aí, e ela precisa ser complementada e cabe ao curso novo, aos estudantes que estão aqui, os professores que estão aqui. O grupo não é reduzido, ele é um número adequado para o início do mestrado e vocês estão de parabéns.

Professor Reginaldo: boa noite professora Jean, seja bem vinda a nossa Universidade, eu gostaria de expressar a nossa alegria de estar vendo esse momento. Eu fui aluno da Universidade Federal de 94-98 no curso de História. Participei de um grupo que a professora Sueli e a professora Marinete fez parte, no NERU; tive a felicidade de após terminar a graduação, fazer uma especialização no departamento de Antropologia e aí fui aluno da Edi Pina, Fátima, Joana e essa especialização que me possibilitou ir pra UFSCAR, estudar com a Marina Cardoso. Eu costumo brincar com meus alunos de Saúde Coletiva, eu sou professor do Departamento de Saúde Coletiva, meu nome é Reginaldo, parte dos alunos da Saúde Coletiva, inclusive estão aqui, meus alunos estão no fundo, outros estão aqui. Eu costumo brincar que você professora Jean é a minha avó, que a Marina Cardoso fazia a gente ler tudo e mais alguma coisa que você escreveu e assim eu quero dizer da alegria do Departamento de Antropologia estar abrindo seus trabalhos trazendo a senhora nesse debate. E aí quando a senhora termina ali anotando nosso campo Antropologia da Saúde ainda de alguma forma aparece perifericamente, por outro lado a gente diz da grandeza do engajamento de quem faz Antropologia da Saúde. Eu fiz uma pesquisa dos portadores falcêmicos com a Marina Cardoso lá em São Paulo, e depois eu fui estudar o mestrado e depois fiz doutorado com os índios do Alto Xingu, tentando entender como que é a Política do Estado de Saúde dialogada ali naquele espaço. De alguma forma, são contribuições de cada um de nós; e quando o Departamento de Antropologia abre os trabalhos com sua palestra, na minha opinião, é um sinal de que nós estamos reconhecendo esse campo. Eu estou dizendo isso, porque eu vim da UFSCAR e a gente de alguma forma dialogava muito, cotidianamente com o pessoal da USP, da UNICAMP, da UNOESP, e vez por outra, via Antropólogos questionando, esse negócio aí é Antropologia mesmoc̉ Esse negócio, até aonde vaic Então os questionamentos, a gente...mas de alguma forma, na nossa opinião, e aí eu sou atualmente do Departamento de Saúde Coletiva. Na Saúde Coletiva dentro das Ciências Sociais, a Antropologia de alguma forma ocupa um espaço enorme e constrói um diálogo enorme. Não é a toa que nós estamos aqui, e aí queremos expressar inclusive para o departamento para os colegas que estão abrindo curso de mestrado que estamos lá a disposição, colegas que são Antropólogos que colaboram, colegas que não são Antropólogos está aqui a nossa chefe do Instituto, mas que é professora do nosso departamento de Ciências Sociais e os outros colegas que colaboram com os estudos de questões indígenas a professora que também colabora e outros que colaboram. A Maria Clara que também colabora para esse debate e estamos lá, abertos contribuindo.

E antes de fazer a pergunta professora, a professora Maria Clara Weiss pediu para te entregar um livro de presente, que é um livro de produção nossa lá do Instituto de Saúde Coletiva, falando um pouco das Estratégias de Saúde no Distrito Sanitário, no caso o Distrito Sanitário aqui de Cuiabá. E a pergunta que eu tenho para anotar é que quando a senhora fala da questão do engajamento aí 
tem o outro lado, como as políticas públicas incorporam aquilo que a gente tenta apontar como possíveis caminhos, especialmente nas políticas de saúde indígena. Eu estive na última Conferência em Brasília, desde 2005 eu venho acompanhando as Políticas do Estado Brasileiro para a população indígena, chamada a atenção diferenciada e aí tanto a senhora quanto seus alunos tem uma gama de contribuição tentando mostrar para o Estado o que seria essa tensão diferenciada, como é que o Estado pode alcançá la se ele assim o quiser; no entanto os avanços, ano sai ano vem ano vai, governo vai, governo vem e os avanços no campo da saúde apesar que a gente tem de reconhecer que os avanços ocorreram no sentido dos índios terem a participação, no entanto na qualidade do serviço ainda é muito a desejar e aí eu sei que a senhora já a anos participa. Marina Cardoso também tem esse papel, junto aos fóruns de saúde em Brasília, Ministério da Saúde, Conselho Nacional de Saúde, eu queria que você falasse como é que tem sido esse diálogo, como é que a senhora tem visto esses avanços ou não avanços junto as Políticas de Saúde Indígena. Tá bomć é isso...mas uma vez eu quero agradecer e parabeniza los pelo programa.

Dra. Jean: Bom, é uma pergunta difícil de responder. A Política de Saúde Indígena é baseada em três pilares: acesso universal, serviços que respeitem a cultura e participação indígena. Eles já se fizeram presentes na $1^{\text {a }}$ Conferência Nacional realizada em Brasília, em 1986. A Conferência foi uma colaboração entre antropólogos, sanitaristas e organizações indígenas envolvidos na questão da saúde. Não podemos subestimar, no estabelecimento desses princípios e nas mudanças na Constituição de 1988, a grande contribuição das organizações indígenas. Porém, durante os anos 1990 houve pouco avanço no sentido de colocar estes princípios num sistema de saúde para os povos indígenas. Acho que o grande problema foi a falta de recursos financeiros. A política em si foi objeto de projetos de lei, decretos e discussões que estabeleceram os princípios da atenção diferenciada. Porém, durante toda a década de 1990, que acompanhei de perto via minha participação na CISI e em pesquisa de meu grupo, além da falta de um desenho administrativo adequado à situação, o governo não aprovou um orçamento adequado para a resolução do problema. Não houve avanços na provisão de serviços nem na operacionalização da atenção diferenciada.

O Programa que gastou e teve mais recursos, inclusive para a saúde indígena, foi o programa de DST/AIDS. O que eu achei de benefício do Programa de DST/AIDS para os povos indígenas não foram as oficinas de multiplicadores, que tiveram como objetivo a educação dos índios para eles educarem seu grupo sobre a doença. Mas o importante, a meu ver, foi a mobilização da participação indígena, cuja presença é central para o avanço maior na política de saúde indígena. A participação indígena tem várias dimensões e críticas. Com a implantação do Subsistema de Saúde Indígena em 1999, a participação indígena aumentou de várias maneiras, mas sua autonomia precisa ser relativizada. Observando as ONG's indígenas que eram encarregadas da gestão de seus programas de saúde, foi possível concluir que não havia autonomia. Em teoria, eles tinham o planejamento e gestão nas mãos, mas de fato não tinham autonomia porque estavam sempre respondendo às demandas da FUNASA. Então, sua participação tem sido ambígua e nem sempre plena. Ao mesmo tempo, podemos dizer que a saúde indígena está na pauta das organizações indígenas e seu conhecimento de como lidar com as políticas do Estado tem se sofisticado.

Agora eu acho que o problema com a saúde indígena, que é uma tendência no Brasil, em geral, é o problema da centralização e burocratização dos programas federais. Foi o problema com o subsistema quando estava nas mãos da 
FUNASA e aparentemente é o caso com a SESAI, ambos sediados e direcionando desde Brasília. Implantando programas de saúde que devem ser operacionalizados de modo igual em todos os lugares, esses órgãos ignoram a diversidade das culturas e ignoram a diversidade da situação dos indígenas no Brasil. Porque são situações muito variáveis entre aqueles que estão lá perdidos no final de algum rio, sem falar português ou ter contato, em comparação com os índios que moram em Santa Catarina ou com os que moram aqui na cidade de Cuiabá. Isso tem resultado num subsistema massificante. Eu observei tentativas de equipes e pesquisadores de criar experiências locais interessantes, mas a demanda da FUNASA sempre foi da estandardização dos programas sem consideração de sua necessidade ou adequação às situações particulares. Podemos pensar isto para os Programas da mulher, de diabetes ou de alcoolismo. Os avanços em atenção diferenciada, que deve atender às necessidades epidemiológicas e culturais particulares, são muito poucos. Agora eu já estou no final da minha carreira. Não pretendo parar de trabalhar com a aposentadoria, mas prefiro trabalhar na escala pequena, onde os avanços são mais possíveis e se pode contar com um diálogo aberto com os profissionais de saúde. Mas esta relação dialógica muitas vezes é problemática. Em geral, o programa de saúde indígena não é considerado um programa exemplar em saúde indígena. Vi isso nas minhas viagens para México e Colômbia. De fato, Brasil tem um dos programas mais extensivos em atenção aos povos indígenas e com bem mais recursos financeiros e humanos. Porém, a centralização, burocratização e padronização vêm impedindo a realização dos princípios estabelecidos pela Política Nacional de Atenção à Saúde dos Povos Indígenas. Bom, não sei se eu respondi, mas a pergunta é difícil.

Dr. Moises: Mais alguma questão?

Alguém da Plateia: Pra mim entender um pouco melhor e se você poder explicar, o que é esse campo da antropologia da saúde; qual o principal objetivo geral dela dentro do contexto geral da saúde, onde ela pretende chegar com esses estudos, com essas pesquisas?

Dra Jean: Vou responder num sentido muito geral. Penso que o que estamos tentando demonstrar é que os processos de saúde e doença não estão enfocados num corpo individual biológico e que, de fato, há outras dimensões nos processos de saúde e doença que remetem à questão social, cultural, coletiva. Nesse sentido, não é para competir com a prática médica, mas ao mesmo tempo tem que reconhecer os limites da biomedicina. Gostaríamos que os profissionais de saúde também entendessem os limites e da mesma maneira os Antropólogos precisam entender os limites do que sabem e fazem. Neste sentido, o subsistema de saúde indígena, como uma rede de atenção primária, não vai resolver os problemas de saúde que os indígenas enfrentam. Não por falhas necessariamente nas técnicas médicas, mas porque suas situações de saúde são consequências da violência estrutural - de não ter terra, de não ter como cultivar, de sofrer mudanças radicais nas organizações sociais e no meio ambiente. $O$ posto de saúde como recurso de atenção é muito importante, mas isso não vai curar os males da população indígena. Não sei se ficou claro, mas tentando explicar, cada campo de conhecimento tem seus limites e às vezes os profissionais de saúde não entendem isso.

Alguém da Plateia: Eu acho muito interessante a forma que você dá, construindo, e eu acho que é uma construção que no Brasil a questão da Antropologia na Saúde como também a Saúde Coletiva uma construção e que pressupõe engajamento e que pressupõe algumas questões que extrapola mesmo o 
campo disciplinar. Eu acho que nós estamos aqui na Saúde Coletiva; tivemos muito colegas Antropólogos contribuindo com disciplinas ou pesquisas aqui no Mato Grosso. No curso de mestrado, e há também algumas questões neste engajamento, nesta participação, na área de ciências humanas e sociais na área de saúde dentro da saúde coletiva, o que infelizmente dentro da CAPES ainda está na grande área das ciências da saúde e aonde hegemonicamente eu tenho os profissionais, e tenho toda a produção avaliada de publicação muito em cima dos critérios não da epidemiologia social, mas da epidemiologia clínica, basicamente é uma tendência dá sobrevivência do programa inclusive em cima das nossas produções, das produções dos alunos que ela deve ser minimamente curtas, 24 meses com algumas questões principalmente quando vou trabalhar com pesquisa qualitativa, e que eu preciso de tempo pra que esse diálogo estabelece com o outro, de determinadas comunidades. E também a gente sofre muito dentro dessa perspectiva a própria dinâmica da produção científica, e das pesquisas que foi imposto no Brasil. E também a questão de quantos pontos conta, e de qual programa está numa revista de antropologia, eu vou ter computado um ponto maior para antropologia, se eu jogo na saúde... então são questões que eu acho que estão postas em termos dos trabalhos interdisciplinares no campo das ciências humanas sociais e saúde, e a gente tem enfrentando e então muitos colegas e muitos trabalhos hegemonicamente, na Saúde Coletiva, eu tenho um ou dois professores que tem formação na área de Antropologia ou Sociologia se não, são outros que se apropriaram com a questão do corpo e estão engajados na saúde coletiva; então é isso também que dá uma dificuldade nesses engajamentos dos profissionais de antropologia, da área da saúde, é uma questão que você deve ter sentido na pele em termos da própria produção não só internacional como nacionalmente. E aí também estava querendo colocar, que essa experiência de estar trabalhando com esses colegas da Antropologia no nosso curso de pós-graduação em Saúde Coletiva foi muito, eu diria gratificante no sentido da gente tá podendo realmente trabalhar Saúde Coletiva, dentro da dimensão que você está colocando, não no corpo biológico, mas trabalhando com as dimensões não só indígenas mas de outros grupos populacionais. E que o ano 2016 o Congresso da ABRASCO vai ser Cuiabá; Cuiabá vai estar sediando, então o Congresso de Ciências Humanas Sociais em Saúde vai ser aqui na UFMT. O que eu acho que é uma coisa muito positiva, nossas parcerias com a Ciências Humanas e Sociais. Então era isso, eu acho seu trabalho belíssimo, eu acho que tem uma questão da paixão eu acho que isso que nos move, esse engajamento, são questões fundamentais para quaisquer pesquisador, obrigada.

Dra. Jean: Só pra comentar, como não foi pergunta - a questão da produção nas ciências está bastante complicada. Meus colegas que trabalham em Departamentos de Farmácia e de Nutrição em Florianópolis, vêm sofrendo, porque eles pesquisam comigo dependendo em parte no método antropológico. Seus departamentos não entendem o tempo nem o tipo de produção. Farmácia é complicada, porque os pesquisadores em farmácia fazem um experimento e cada passo do experimento resulta em um artigo, frequentemente com mais autores que páginas. Minha colega na Farmácia tem sido bastante penalizada por realizar pesquisas de campo de longa duração. Pensando em outro aspecto, um que ainda não atingiu plenamente a Antropologia mas que deve chegar, é a tendência de pensar que o fazer ciência só tem uma maneira. Além de enfatizar uma suposta objetividade universal, tem desdobramentos na maneira de escrever ciência para as revistas. Por exemplo, os artigos submetidos aos Cadernos de Saúde Pública, a meu ver, precisam se conformar a um tamanho e padronização 
que está eliminando a possibilidade de discussões reflexivas ou críticas. $\mathrm{O}$ formato do artigo científico constrói um mundo de dados como se esses dados fossem uma realidade e não são. São maneiras de captar as realidades, e as realidades através dos dados quantitativos e "objetivos" são construções tão quanto as através da descrição etnográfica. Eu tenho uns artigos nos Cadernos de Saúde Pública e estou mais e mais frustrada com as limitações para meus artigos que considero ser de ciências sociais mas que pretendem estar em diálogo com a saúde, particularmente as implicações políticas e sociais das pesquisas. Tem pouco espaço para esta discussão. 


\section{Referências}

ALMEIDA FILHO, N. de 2001. For a General Theory of Health: Preliminary Epistemological and Anthropological Notes. Cadernos de Saúde Pública. 17(4): 753-799

ARRUTI, José M. 1997. Uma antropologia Mameluca a partir de Darcy Ribeiro, Lusofonia - Revista da Faculdade de Letras da Universidade de Lisboa, 21/22 (1): 301-312.

BERTOLLI FILHO, C. 2003. A sociologia de Gilbeto Freyre e a educação para a saúde. Ciência \& Educação, 9 (1): 105-121.

BONFIL BATALLA, G. 1966. Conservative thought in applied anthropology: a critique. Human Organization, 25: 89-92.

BRICEÑO-LEÓN, R. (org.). 1999. Ciencias sociales y salud en América Latina: un Balance. Caracas: Fundación Polar.

BRICEÑO-LEÓN, R., MINAYO, M.C. de S., COIMBRA Jr, C.E.A. 20oo. Salud y Equidad: Una mirada desde las ciências sociales. Rio de Janeiro: Editora Fiocruz.

BRIEHL, J. 2010. La epidemiologia crítica: una nueva forma de mirar la salud en el espacio urbano. Revista de Saúde Colectiva 61(1): 83-101.

BRIGGS, C. L. 2005. Perspectivas críticas de salud y hegemonia comunicativa: aperturas progressistas, enlaces letales. Revista de Antropología Social, 14: 101124.

BRONFMAN, M. e CASTRO, R. 1999. Salud, Cambio Social y Política: Perspectivas desde América Latina. Mexico, DF: Edmex.

CÁCERES, Carlos, CUETO, M., RAMOS, M. e VALLENAS, S. 2003. La Salud como Derecho Ciudadano: Perspectivas y Propuestas desde América Latina. Lima: Facultad de Salud Pública y Administración de la Universidad Peruana Cayetano Heredia.

CARDOSO DE OLIVEIRA, Roberto. 1998. O Trabalho do Antropólogo. São Paulo: Editora UNESP.

CARDOSO DE OLIVEIRA, R. 1999-2000. "Peripheral Anthropologies 'versus' Central Anthropologies. Epistemological Dimensions”. Journal of Latin American Anthropology, 4 (2): 10-30.

FOLLÉR, M.L. 2004. Intermedicalidade: a zona de contato criada por povos indígenas e profissionais de saúde. In: LANGDON, E. J., GARNELO, L. (org.). Saúde dos povos indígenas: reflexões sobre antropologia participativa. Rio de Janeiro: Editora ContraCapa/ABA. pp. 129-148.

FREYRE, G. 1967. Sociologia da Medicina. Breve introdução ao estudo dos seus princípios, dos seus métodos e das suas relações com outras sociologias e com outras ciências. Lisboa: Fundação Calouste Gulbenkian.

GREENE, S. 1998. The shaman's needle: development, shamanic agency, and intermedicality in Aguaruna Lands, Peru. American Ethnologist 25(Supl.4):634-658.

HARO, J. A. 2011. Epidemiología sociocultural. Un diálogo en torno a su 
sentido, métodos y alcances. Buenos Aires: Lugar Editorial/Centro de Estudios en Salud y Sociedad, El Colegio de Sonora.

KLEINMAN, A.M. 1973. Some issues for a comparative study of medical healing. International Journal of Social Psychiatry 19:159-165

LANGDON, E. J. 1994. Representações de doença e itinerário terapêutico entre os Siona da Amazônia colombiana. In: Santos RV, Coimbra C, (org.) Saúde e Povos Indígenas. Rio de Janeiro: Fiocruz. p.115-142.

LANGDON, E. J. 2005. A doença como experiência: a construção da doença e seu desafio para a prática médica. In: Baruzzi, R, Junqueira, C., (org.) Parque Indígena do Xingu: Saúde, Cultura e História. São Paulo: UNIFESP/Terra Virgem. p. 115-134

LANGDON, E. J. e M-L. Follér 2012. Anthropology of Health in Brazil: A Border Discourse. Medical Anthropology 31 (1): 4-28.

LANGDON, E. J., Follér, M. L., e MALUF, S. W. 2012. Um balanço da antropologia da saúde no Brasil e seus diálogos com as antropologias mundiais. Anuário Antropológico 2011-I. p. 51-89.

MEGGERS, B. J. 1968. Forward. In: RIBEIRO, D. The Civilizational Process. New York: Harper Torchbooks. P. v-x.

MENÉNDEZ, E. L. 1982. El proceso de alcoholización: revisión critica de la produción socioantropológica, histórica y biomédica en America Latina. Cuaderno de la Casa Chata 57: 61-94.

MENÉNDEZ, E. L. 2003. Modelos de atención de los padecimientos: de exclusiones teóricas y articulaciones prácticas. Ciências e Saúde Coletiva 8(Supl.1):185-208

MENÉNDEZ, E. L. 2009. Sujeitos, Saberes e Estruturas: uma introdução ao enfoque relacional no estudo da saúde coletiva. São Paulo: HUCITEC.

MENÉNDEZ, E. L. 2012. Metodología cualitativa: Varios problemas y reiteradas omisiones. Index de Enfermeria/Primer-Segundo trimestre 21(1-2):62-68.

MINAYO, M. C. de S. e COIMBRA Jr, C.E.A. 2005. Críticas e Atuantes: Ciências Sociais e Humanas em Saúde na América Latina. Rio de Janeiro: Editora Fiocruz.

MONTEIRO, A.L. e VILLELA, W. V. 2009. A Criação do Programa Nacional de DST e AIDS como marco para a inclusão da ideia de Direitos Cidadãos na Agenda Governamental Brasileira. Psicologia Política, 9 (17): 25-45.

NUNES, 1999. Sobre a Sociologia da Saúde. Saúde em Debate 128. São Paulo: HUCITEC.

NUNES, E.D. 1989. As Contribuições de Juan César García às Ciências Sociais em Saúde. In: NUNES, E.D. (org.) Juan César García: Pensamento Social em Saúde na América Latina. São Paulo: Cortez Editora/ABRASCO. P. 11-41.

ORTNER, S. 2007. Uma atualização da teoria da prática. In: Grossi MP, Eckert C, Fry P, (org) Conferências e diálogos: saberes e práticas antropológicas. Blumenau: Nova Letra.

PORTELA GUARIN, H. 2008. La Epidemiologia intercultural. Argumentaciones, requerimientos y propuestas. Popayan: Editorial 
Universidad del Cauca.

QUEIROZ, M. S, e CANESQUI, A. M. 1986a Contribuições da antropologia à medicina: uma revisão de estudos no Brasil. Revista de Saude Publica 20(Supl.2):141-151.

QUEIROZ, M. S. e CANESQUI, A. M. 1986b. Antropologia da medicina: uma revisão teórica. Revista de Saude Publica 20(Supl.2): 152-164.

RESTREPO, E. e ESCOBAR, A. 2005. Other Anthropologies and Anthropology Otherwise: Steps to a World Anthropology Network. Critique of Anthropology, 25 (2):99-128.

RIBEIRO, A. M. 2011. Darcy Ribeiro e o enigma Brasil: um exercício de descolonização epistemológica. Sociedade e Estado, 26 (2): 23-49.

WEBER, M. 1986. A Objectividade do Conhecimento nas Ciências Sociais. In G. Cohn, (org) Weber, Coleção grandes Cientistas Sociais. São Paulo: Editora Ática. pp. 79-128.

YOUNG, A. 1976. Some implications of medical beliefs and practices for social anthropology. American Anthropologist, 78(1): 5-24. 